\title{
Profil Tes Fungsi Hati pada Pasien Gagal Jantung Kongestif di RSUP Prof. Dr. R. D. Kandou Periode Januari - Desember 2012
}

\author{
${ }^{1}$ Ferdinand I.Parera \\ ${ }^{2}$ Agnes L. Panda \\ ${ }^{2}$ Ventje Kawengian
}

\author{
${ }^{1}$ Kandidat Skripsi Fakultas Kedokteran Universitas Sam Ratulangi Manado \\ ${ }^{2}$ Bagian Ilmu Penyakit Dalam Fakultas Kedokteran Universitas Sam Ratulangi Manado \\ Email: squall_enix@yahoo.com
}

\begin{abstract}
Heart failure is a clinical syndrome characterized by shortness of breath and fatique during activity or at rest, caused by structural abnormalities or heart dysfunction. Left and right heart failure that occur at the same time is called congestive heart failure, and it can also be associated with impaired liver function, such as elevated AST and ALT levels. This study was aimed to obtain the liver function among patients with congestive heart failure at Prof. Dr. R. D. Kandou by using total sampling method. Samples were patients with congestive heart failure at Prof. Dr. R. D. Kandou Hospital in 2012. Data of congestive heart failure patients were divided into liver function, gender, age, congestive heart failure, and New York Heart Association (NYHA) functional category recorded in the outpatient medical records. The results showed that there were 54 patients with congestive heart failure (33 males and 21 females); only 32 of them had liver function test data. Of the 32 patients, 9 patients showed increased liver function test less than twice of normal value and 2 patients had more than twice of normal value of liver function tests. Conclusion: The majority of patients with congestive heart failure had normal liver function test.
\end{abstract}

Keywords: congestive heart failure, liver function test, ALT, AST, NYHA functional classes

\begin{abstract}
Abstrak: Gagal jantung merupakan sindrom klinis ditandai dengan sesak napas dan kelambanan (saat aktivitas atau saat istirahat) yang disebabkan oleh kelainan struktur atau disfungsi jantung. Gagal jantung kiri dan gagal jantung kanan yang terjadi bersamaan disebut gagal jantung kongestif yang bisa disertai gangguan fungsi hati (peningkatan kadar AST dan ALT). Penelitian ini bertujuan untuk mengetahui angka kejadian penderita dengan gagal jantung kongestif disertai gangguan tes fungsi hati di poliklinik jantung. Jenis penelitian ialah deskriptif retrospektif. Sampel ialah penderita dengan gagal jantung kongestif di Poliklinik Jantung RSUP Prof. Dr. R. D. Kandou selama periode Januari-Desember 2012. yang diperoleh dengan metode total sampling. Data penderita gagal jantung kongestif dibagi atas tes fungsi hati, jenis kelamin, kelompok usia, faktor penyebab gagal jantung kongestif, dan klasifikasi fungsional NYHA (New York Heart Association) yang tercantum dalam buku register/rekam medis rawat jalan. Hasil penelitian memperlihatkan sebanyak subjek 54 penderita gagal jantung kongestif (33 laki-laki dan 21 perempuan), tetapi hanya 32 penderita diantaranya yang memiliki data tes fungsi hati. Dari 32 penderita tersebut, 9 penderita mengalami peningkatan kurang dari dua kali nilai normal tes fungsi hati dan 2 penderita lebih dari dua kali nilai normal tes fungsi hati. Simpulan: Sebagian besar penderita dengan gagal jantung kongestif mempunyai tes fungsi hati dalam batas normal.
\end{abstract}

Kata kunci: gagal jantung kongestif, tes fungsi hati, kelas fungsional NYHA 
Pada tahun 2005 prevalensi gagal jantung sebesar $2-2,5 \%$ pada semua usia, dan pada usia di atas 80 tahun prevalensi gagal jantung $>10 \%$ terjadi di Eropa. Pada tahun 2006, prevalensi gagal jantung di Amerika Serikat sebesar 2,6\%; 3,1\% pada laki-laki dan $2,1 \%$ pada perempuan. ${ }^{1}$ Penyakit jantung koroner (PJK) yang merupakan penyebab tersering terjadinya infark miokard pada usia kurang dari 75 tahun disusul oleh hipertensi dan diabetes melitus, menyebabkan terjadinya disfungsi miokard dan bila tidak ditangani dengan baik dapat mengakibatkan gagal jantung, Berdasarkan data dari rumah sakit Palembang, hipertensi merupakan penyebab terbanyak gagal jantung, disusul PJK dan gangguan katub jantung. ${ }^{2}$

Kongestif pasif dari gagal jantung menyebabkan bendungan aliran darah hati, selanjutnya meningkatkan tekanan vena sentralis yang pada akhirnya meningkatkan enzim fungsi hati. Pentingnya prognosis dari kelainan tes fungsi hati telah bervariasi antara uji yang telah dipublikasikan, juga prediksi nilai yang tidak baik telah banyak ditemukan pada pasien dengan gagal jantung. ${ }^{3}$ Angka kejadian gagal jantung berdasarkan wawancara terdiagnosis dokter dari 33 provinsi di Indonesia sebesar 0,13\% dan yang terdiagnosis dokter atau gejala $0,3 \%{ }^{4}$

Tingginya angka kejadian gagal jantung serta kurangnya data mengenai keadaan ini di Sulawesi Utara, khususnya di Manado mendorong peneliti untuk melakukan penelitian ini yang bertujuan untuk mengetahui profil tes fungsi hati pada pasien dengan gagal jantung kongestif di Poliklinik Jantung RSUP Prof. Dr. R. D. Kandou Manado selama satu tahun, yaitu periode Januari 2012-Desember 2012.

\section{METODE PENELITIAN}

Jenis penelitian ini ialah retrospektif deskriptif dengan menggunakan data rekam medis dari status pasien gagal jantung kongestif di Poliklinik Jantung RSUP Prof. Dr. R. D. Kandou Manado selama satu tahun, yaitu periode Januari 2012Desember 2012. Populasi dan sampel dari penelitian ini ialah seluruh pasien dengan gagal jantung kongestif di Poliklinik Jantung RSUP Prof. Dr. R. D. Kandou Manado periode Januari 2012-Desember 2012.

Variabel penelitian ialah distribusi frekuensi pasien dengan gagal jantung kongestif berdasarkan: pasien gagal jantung kongestif disertai gangguan tes fungsi hati; jenis kelamin laki-laki dan perempuan; usia ( $<20$ tahun, 20-29 tahun, 30-39 tahun, 4049 tahun, 50-59 tahun, 60-69 tahun, dan $\geq 70$ tahun); faktor penyebab (PJK, katub jantung/valvular; hipertensi; penyebab lain); dan klasifikasi NYHA (kelas I s/d IV).

Data yang diperoleh dari rekam medis pasien diolah dan disajikan dalam klasifikasi tabel dan grafik. Nilai batas normal ALT ialah $12-\leq 47$ U/L sedangkan AST ialah $12-\leq 37$ U/L. ${ }^{5,6}$

\section{HASIL PENELITIAN}

Pada penelitian ini didapatkan 54 penderita gagal jantung kongestif, tetapi hanya 32 penderita diantaranya memiliki pemeriksaan tes fungsi hati. Tabel 1 menunjukkan peningkatan tes fungsi hati pada 9 penderita $(28,12 \%)$, tetapi yang meningkat lebih dari 2 kali hanya 2 penderita. Sebagian besar hasil pemeriksaan tes fungsi hati pada penderita gagal jantung kongestif masih dalam batas normal yaitu 21 penderita $(65,63 \%)$.

Tabel 1. Distribusi penderita gagal jantung kongestif berdasarkan tes fungsi hati

\begin{tabular}{lcc}
\hline $\begin{array}{l}\text { Tes fungsi hati } \\
\text { (ALT/AST) }\end{array}$ & Jumlah & $\mathbf{( \% )}$ \\
\hline Meningkat $\uparrow<2$ kali & 9 & 28,12 \\
Meningkat $\uparrow>2$ kali & 2 & 6,25 \\
Dalam batas normal & 21 & 65,63 \\
Total & 32 & 100 \\
\hline
\end{tabular}

Keterangan : nilai batas normal (ALT $=12-\leq 47$ $\mathrm{U} / \mathrm{L} ; \mathrm{AST}=12-\leq 37 \mathrm{U} / \mathrm{L})^{5,6}$

Berdasarkan data, dari 54 penderita gagal jantung kongestif, pasien laki-laki 33 penderita $(61,12 \%)$ sedangkan perempuan 21 penderita $(38,88 \%)$ (Gambar 1). 


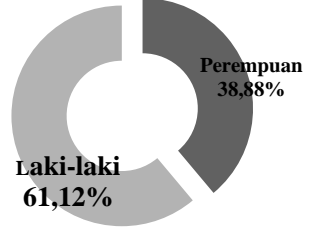

Gambar 1. Persentase penderita gagal jantung kongestif berdasarkan jenis kelamin
Tabel 2 memperlihatkan bahwa seorang penderita $(1,85 \%)$ berada dalam golongan usia $\leq 20$ tahun, 2 penderita $(3,71 \%)$ dalam golongan usia 21-30 tahun, 2 penderita $(3,71 \%)$ dalam golongan usia 31-40 tahun, 2 penderita $(3,71 \%)$ dalam golongan usia 41-50 tahun, 10 penderita $(18,55 \%)$ dalam golongan usia 51-60 tahun, 18 penderita $(33,33 \%)$ dalam golongan usia 61-70 tahun, dan 19 penderita $(35,13 \%)$ dalam golongan usia $\geq 71$ tahun.

Tabel 2. Distribusi penderita gagal jantung kongestif berdasarkan golongan usia

\begin{tabular}{ccccccc}
\hline \multirow{2}{*}{$\begin{array}{c}\text { Golongan } \\
\text { usia }\end{array}$} & \multicolumn{2}{c}{ Laki-Laki } & \multicolumn{2}{c}{ Perempuan } & Jumlah & \multirow{2}{*}{$(\%)$} \\
\cline { 2 - 5 } & Jumlah & $(\%)$ & Jumlah & $(\%)$ & & \\
\hline$\leq 20$ tahun & 1 & 1,85 & - & - & 1 & 1,85 \\
$21-30$ tahun & - & - & 2 & 3,7 & 2 & 3,71 \\
$31-40$ tahun & 1 & 1,85 & 1 & 1,85 & 2 & 3,71 \\
$41-50$ tahun & 2 & 3,7 & - & - & 2 & 3,71 \\
$51-60$ tahun & 6 & 11,1 & 4 & 7,4 & 10 & 18,55 \\
61-70 tahun & 11 & 20,35 & 7 & 12,95 & 18 & 33,33 \\
$\geq 71$ tahun & 12 & 22,2 & 7 & 12,95 & 19 & 35,13 \\
Total & 33 & 61,12 & 21 & 38,88 & 54 & 100 \\
\hline
\end{tabular}

Tabel 3 memperlihatkan sebagian besar penderita gagal jantung kongestif disebabkan oleh hipertensi sebanyak 27 penderita (50\%), diikuti PJK 11 penderita $(20,38 \%)$, penyakit jantung katub 10 penderita $(18,51 \%)$, dan akibat penyebab lain 6 penderita $(11,11 \%)$.

Tabel 3. Distribusi penderita gagal jantung kongestif berdasarkan faktor penyebab

\begin{tabular}{lcc}
\hline Faktor penyebab & Jumlah & $\mathbf{\%}$ \\
\hline Hipertensi & 27 & 50,00 \\
PJK & 11 & 20,38 \\
Penyakit jantung katub & 10 & 18,51 \\
Penyebab Lain & 6 & 11,11 \\
Total & 54 & 100 \\
\hline
\end{tabular}

\section{BAHASAN}

Dari 4327 total kunjungan pasien dengan diagnosis utama gagal jantung kongestif yang terdaftar di Instalasi Rawat Jalan RSUP Prof. Dr. R. D. Kandou Manado selama tahun 2012, terdapat 4014 kasus lama dan sisanya 313 merupakan
Tabel 4 menunjukan bahwa penderita dengan gagal jantung kongestif yang datang untuk mendapatkan pelayanan di poliklinik jantung terbanyak berada pada fungsional kelas II $(66,66 \%)$, diikuti fungsional kelas I $(27,78 \%)$ dan fungsional kelas III $(5,56 \%)$.

Tabel 4. Distribusi penderita gagal jantung kongestif berdasarkan klasifikasi NYHA

\begin{tabular}{lcc}
\hline Klasifikasi NYHA & Jumlah & \% \\
\hline Fungsional kelas I & 14 & 27,78 \\
Fungsional kelas II & 37 & 66,66 \\
Fungsional kelas III & 3 & 5,56 \\
Fungsional kelas IV & - & - \\
Total & 54 & 100 \\
\hline
\end{tabular}

kasus baru. Hal ini berarti dari total kunjungan pasien terdapat $7,24 \%$ kasus baru di tahun 2012.

Patofisiologi primer yang menyangkut gangguan fungsi hati pada gagal jantung kongestif, salah satunya disebabkan oleh sumbatan tidak langsung akibat tekanan 
pengisian meningkat atau perfusi ke hati yang kurang sebagai konsekuensi curah jantung yang melemah. Kongestif pasif pada hati karena tingginya tekanan pada vena sentral, dapat meningkatkan enzimenzim hati (ALT, AST). Kongesti hati dapat menyebabkan jaundice, kelainan enzim hati, dan penurunan dari fungsi fisiologi hati yang terkena. ${ }^{7}$

Dalam penelitian ini ditemukan 9 $(28,12 \%)$ dari 32 penderita gagal jantung kongestif mengalami peningkatan tes fungsi hati (AST, ALT); hanya 2 penderita $(6,25 \%)$ yang meningkat $<2$ kali nilai normal, sedangkan sisanya 21 penderita $(65,63 \%)$ masih dalam batas normal. Alvares dan Mukherjee $^{7}$ menemukan ketidak normalan ini mencapai puncaknya pada 1 sampai 3 hari setelah permulaaan hepatitis iskemik kardiogenik dan kembali normal tidak lebih dari 5-10 hari dari timbulnya gangguan. Keadaan ini mungkin berhubungan dengan jenis kelamin, umur, factor penyebab, juga berat ringannya atau derajat gagal jantung kongestif.

Kelainan hati akibat dari gagal jantung kongestif disebabkan oleh tiga proses utama, yaitu: peningkatan tekanan vena hepatika, penurunan aliran darah hati, dan penurunan tingkat saturasi oksigen arteri. Peningkatan tekanan vena diteruskan melalui vena hepatica sampai ke venula hepatika, dan akan menyebabkan menurunnya pasokan oksigen dan nutrisi ke hepatosit, sehingga mengakibatkan kerusakan hepatosit. ${ }^{8}$

Dalam penelitian ini ditemukan persentase jumlah penderita laki-laki tidak jauh berbeda dengan persentase jumlah penderita perempuan namun tidak signifikan. Hasil ini selaras dengan yang ditemukan oleh Dubey et al. ${ }^{9}$ yaitu angka kejadian gagal jantung pada laki-laki lebih tinggi dibanding perempuan, namun secara keseluruhan prevalensi keduanya hampir sama. Dari 54 kasus di poliklinik jantung ditemukan 33 penderita $(61,12 \%)$ laki-laki dan 21 penderita $(38,88 \%)$ perempuan, dengan kata lain perbandingan antara lakilaki dan perempuan 1,57:1.

Gagal jantung sering dianggap sebagai suatu kondisi pada lansia karena 10 dari 1000 penduduk terjadi pada 65 tahun keatas. ${ }^{9}$ Hal ini juga ditemukan dalam penelitian ini dengan didapatkannya golongan usia 61-70 tahun sebagai nilai tengah dari data usia penderita di poliklinik jantung. Dari 54 kasus yang dianalisis ditemukan 19 kasus $(33,33 \%)$ berusia $\geq 71$ tahun, diikuti 18 kasus $(35,13 \%)$ pada golongan usia 61-70 tahun, kemudian golongan usia 51-60 tahun dengan 10 kasus (18,55\%), sedangkan golongan usia 21-30, 31-40 dan 41-50 tahun masing-masing di dapatkan 2 kasus $(3,71 \%)$ namun belum signifikan. Hanya ditemukan 1 kasus $(1,85 \%)$ pada golongan usia $\leq 20$ tahun; hal itu sering disebabkan oleh penyakit jantung kongenital.

Dubey et al. $^{9}$ melaporkan bahwa penyebab gagal jantung kongestif pada 93 kasus $(36.5 \%)$ dari 255 kasus disebabkan oleh PJK. Hal tersebut tidak sejalan dengan penelitian ini yang mendapatkan penyebab utama dari gagal jantung kongestif yaitu 27 dari 54 kasus (50\%) disebabkan oleh hipertensi sedangkan PJK menempati urutan ke-2 (28,38\%), diikuti penyakit jantung katub $(18,51 \%)$, dan penyebab lainnya seperti kardiomiopati, penyakit jantung kongenital dsb $(11,11 \%)$.

Faktor penting lainnya ialah penilaian berat ringannya atau derajat gagal jantung kongestif. Untuk melihat derajat gangguan kapasitas fungsional dari gagal jantung, pertama kali diperkenalkan oleh New York Heart Association (NYHA) tahun 1994. ${ }^{10}$ Pada penelitian ini ditemukan umumnya pasien yang datang berobat ke poliklinik jantung tergolong kelas fungsional II (37 dari 54 kasus) atau gejala berupa fatique, palpitasi, dan dispnea yang timbul saat aktivitas fisik yang biasa. Perbedaan yang signifikan juga terlihat pada kelas fungsional I dan IV di Poliklinik jantung (kelas I dengan 14 kasus sedangkan kelas IV tidak ditemukan dalam penelitian ini).

\section{SIMPULAN}

Dari hasil penelitian dan bahasan dapat disimpulkan bahwa sebagian besar penderita gagal jantung kongestif di 
poliklinik RSUP Prof. Dr. R. D. Kandou periode Januari-Desember 2012 memiliki tes fungsi hati normal.

\section{SARAN}

1. Diperlukan peneltian lebih lanjut dengan jumlah sampel yang lebih besar dan rentang waktu yang lebih lama.

2. Diperlukan ketelitian dan penyempurnaan dalam mengisi kelengkapan data rekam medis pasien rawat jalan, agar data penelitian bisa lebih lengkap.

\section{DAFTAR PUSTAKA}

1. Teerlink J. Acute heart failure. In: Scharschmidt BF, editor. Internal Medicine. New York: Cambridge University Press, 2007.

2. Ghanie A. Gagal jantung kronik. In: Sudoyo AW, Setiyohadi B, Alwi, Simadibrata M, Setiati S, editors. Buku Ajar Ilmu Penyakit Dalam (5th ed). Jakarta: Interna Publishing, 2009; p. 1596-7.

3. Nikolaou M, Parissis J, Yilmaz MB, Seronde MF, Kivikko M, Laribi S, et al. Liver function, clinical profile, and outcome in acute decompensated heart failure.
Eur Heart J. 2013;34:742-9.

4. Riset Kesehatan Dasar (RISKESDAS) Kementerian Kesehatan, 2013; p. 90-2.

5. Safitri A, editor. At a glance Anamnesis dan Pemeriksaan Fisik. Jakarta: Erlangga, 2003.

6. Putra HL, Andriati. Gagal jantung. In: Pedoman Diagnosis dan Terapi. (1st ed). Surabaya: FK Unair, 2008.

7. Alvares AM, Mukherjee D. Liver abnormalities in cardiac disease and heart failure. Int $\mathbf{J}$ Angiol. 2011;20(3):135-42.

8. Samsky MD, Patel CB, DeWald TA, Smith AD, Felker M, Rigers JG, et al. Cardiohepatic interaction in heart failure. J ACC. 2013;61(24): 2397-405.

9. Dubey L, Sharma SK, Sharma AK. Clinical profile of patients hospitalized with heart failure in Bharatpur, Nepal. J Cardiovasc Thoracic Res. 2012;4(4):103-5.

10. Manurung D. Gagal jantung akut. In: Sudoyo AW, Setiyohadi B, Alwi, Simadibrata M, Setiati S, editors. Buku Ajar Ilmu Penyakit Dalam (5th ed). Jakarta: Interna Publishing, 2009; p. 1586. 